\title{
Two new genera of Desmiphorini (Coleoptera, Cerambycidae, Lamiinae) with description of a species with non-retractile parameres
}

\author{
Francisco Eriberto de Lima Nascimento ${ }^{1,2}$ \& Antonio Santos-Silva ${ }^{1,3}$
}

1 Universidade de São Paulo (USP), Museu de Zoologia (MZUSP). São Paulo, SP, Brasil.

2 ORCID: http://orcid.org/0000-0002-5047-8921. E-mail: eribnascimentofl@gmail.com

3 ORCID: http://orcid.org/0000-0001-7128-1418. E-mail: toncriss@gmail.com

\begin{abstract}
In this study, two new genera of Desmiphorini (Lamiinae) are proposed: Cleidaria gen. nov., to include Cleidaria cleidae sp. nov. from the state of Chiapas in Mexico, and Obscenoides gen. nov. for Desmiphora (D.) compta Martins \& Galileo, 2005. The shape of tarsal claws of Cleidaria cleidae sp. nov. (abruptly narrowed from basal half) is so far, not found in any current genera of the tribe. With respect to Obscenoides compta (Martins \& Galileo, 2005) comb. nov., the genitalia of males have an unusual shape with non-retractile parameres. The character combination related to this genital structure is unknown to us in other species in the family, and hypotheses about its function are suggested.
\end{abstract}

Key-Words. Genital morphology; Longhorned beetles; New taxa; Taxonomy.

\section{INTRODUCTION}

Lamiinae (Cerambycidae), also known as flatfaced longhorns, with more than 21,000 described species in about 3,000 genera and 87 tribes is the largest subfamily of Cerambycidae occurring worldwide (Tavakilian \& Chevillotte, 2019).

Currently, the tribes of Lamiinae are differentiated by character sets from which, one of the most used is the shape of tarsal claws, classified as: divergent, divaricate, bifid or appendiculate (Linsley \& Chemsak, 1984). However, the current diagnosis of Lamiinae's tribes is still mostly based on Lacordaire (1868-1872), and the fragility and artificiality of almost all these tribes are well known and have been frequently commented upon. According to Ślipiński \& Escalona (2013): "Based on our preliminary molecular and morphology-based research on Australian Cerambycidae we believe that the current tribal classification of Lamiinae is artificial and should be abandoned. It was devised by S. Breuning based on a combination of a few adult characters without any phylogenetic signal and has been perpetuated and 'adjusted' by a few cerambycid workers ever since. It is also not a practical system because many genera cannot be placed in recognized tribes, thus creating serious obstacles for further research." Likewise, Linsley \& Chemsak (1984) argue that the current definitions of some tribes, especially based on the works of Breuning do not take into account adaptive convergences and use superficial characters to subordinate taxa.

Among these tribes, Desmiphorini Thomson, 1860 is not an exception, and its "boundaries" are quite questionable, especially when compared with Acanthoderini Thomson, 1860. "Typical" Desmiphorini (like Desmiphora Audinet-Serville, 1835 and Estola Fairmaire \& Germar, 1859) and "typical" Acanthoderini (as Acanthoderes AudinetServille, 1835 and Aegomorphus Haldeman, 1847) species are very distinct. However, some genera included in these two tribes are very similar, making impracticable to know to which tribe they can be objectively allocated, as Cotycicuiara Galileo \& Martins, 2008, originally described in Desmiphorini, and later transferred to Acanthoderini by Tavakilian \& Néouze (2013).

According to Monné \& Wappes (2014), the diagnosis given by Breuning (1974) for Desmiphorini (Rhodopinini sensu auct.) is contradictory and useless and only the divaricate tarsal claws make sense. Currently, Desmiphorini includes about 1,500 species distributed in 304 genera, recorded worldwide (Roguet, 2019).

In this work, two new genera are described and illustrated: Cleidaria gen. nov., to include Cleidaria cleidae sp. nov. from the state of Chiapas 
in Mexico, and Obscenoides gen. nov. for Desmiphora (D.) compta Martins \& Galileo, 2005. Additionally, we commented and described the morphology of the genitalia of Obscenoides compta comb. nov., which has non-retractile parameres, character unknown by us in any other species of the family. The two genera described here are placed in Desmiphorini because they share general appearance similar to the classical appearance and features of the tribe (not similar to Acanthoderini). Furthermore, Obscenoides gen. nov. is very similar to Desmiphora Audinet-Serville, 1835. Cleidaria gen. nov. shares some characters with Eupogonius LeConte, 1852. However, only more detailed studies may clarify the genera closest to the new genera.

\section{MATERIAL AND METHODS}

Photographs were taken in the Museu de Zoologia da Universidade de São Paulo, São Paulo, Brazil (MZSP), with a Canon EOS Rebel T3i DSLR camera, Canon MP-E $65 \mathrm{~mm}$ f/2.8 1-5× macro lens, controlled by Zerene Stacker software. Measurements were taken in millimeters using a measuring ocular Hensoldt/Wetzlar - Mess 10 in the Leica MZ6 stereomicroscope, also used in the study of the specimen. The plates were edited with GIMP 2.10.10 (GNU Image Manipulation Program) and Inkscape 0.48.4.

For dissection, the abdomen of the dry specimen was removed and heated in hot $10 \% \mathrm{KOH}$ solution for approximately 5-10 minutes, and then the genital parts were removed through a cut at one side of abdomen. The genitalia were reheated in the same solution for approximately 3 minutes. After that, the structures were washed in acetic acid. Finally, the abdomen was glued back on the specimen and the genitalia was stored in microvials with glycerin. The studied specimens are deposited at MZSP.

\section{RESULTS}

\section{Cleidaria gen. nov.} (Figs. 1-5)

Type species: Cleidaria cleidae sp. nov., here designated.

\section{Description}

Male: Small size (length: $5.8 \mathrm{~mm}$ ), cylindrical. Head wide, not retractile; frons distinctly transverse; palpi slender, unequal, with apical segment pointed; antennal tubercles widely separated, slightly elevated; eyes emarginate, coarsely faceted; distance between upper eye lobes slight larger than width of one lobe; lower eye lobes distinctly longer than gena; antennae slender, with long, erect, moderately abundant and long setae ventrally, also present dorsally in basal segments, but sparser; scape elongate, moderately widened toward apex; antennomere III slightly longer than IV. Prothorax slightly wider than long; sides with distinct central tubercle. Pronotum not tuberculate. Procoxal cavities closed behind. Central area of prosternal process about 0.25 times the diameter of procoxal cavity. Elytra parallel-sided in basal 3/4, gradually narrowed in distal quarter; elytra apices unarmed, individually rounded; not carinate; with long, erect setae throughout. Membranous wings present. Femora moderately clavate; tarsi short; tarsal claws (Fig. 4) abruptly narrowed from basal half at inner side, forming a rounded tooth. Abdominal ventrite I longest, II-IV shorter, subequal in length, $\mathrm{V}$ slightly longer than IV.

Female: Unknown.

Etymology: Latin, suffix "aria" - belonging to, added to the first name of Cleide Costa. Feminine gender.

Remarks: Lacordaire (1869) was the first to use the shape of tarsal claws to separate supraspecific groups in Lamiinae and its classification is one of the most commonly followed in the family. The shape of the tarsal claws of the new species is divaricated, as the other species of the tribe. However, due to the particular shape of tarsal claws and the importance of this character in family classification, we prefer to propose a new genus to allocate the new species.

Cleidaria gen. nov. differs from all other genera of American Desmiphorini by the tarsal claws (Fig. 4) distinctly and abruptly narrowed from basal half forming a rounded tooth (In other genera, the claws are gradually acuminate towards apex). Accordingly, the new species cannot be confused with any other known species of Desmiphorini or even American Lamiinae. The holotype of the type species, the only known specimen, is damaged. Thus, it is not possible to provide information on the antennal length, and appearance of the last antennomeres. However, the antennae are expected to be slightly longer than the body, and the distal antennomeres are likely filiform and unmodified similar to most species in the tribe. The genus with the most similar appearance is Eupogonius LeConte, 1852, especially by the shapes of prothorax and elytra, and proportions between them. However, the shape of the tarsal claws does not allow inclusion of the new species.

\section{Cleidaria cleidae sp. nov.} (Figs. 1-5)

Type material: HOLOTYPE ơ (MZSP): MEXICO, Chiapas: Motozintla (Finca de la Victoria), 06.V.1962, M.A. Vulcano col.

\section{Description}

Male: Integument mostly dark brown; anteclypeus testaceous anteriorly; pedicel, basal $4 / 5$ of antennomere III, and basal $3 / 4$ of antennomere IV reddish brown; elytra gradually reddish brown toward apex; tibiae reddish brown except dark basal and distal areas. Missing segments: antennomeres IX-XI of left antenna; antennomeres VIII-XI 
of right antenna; tarsomere $\mathrm{V}$ of right mesotarsus; left metatarsus.

Head: Frons moderately fine and densely punctate; with moderately bristly white pubescence not obscuring integument (partially lost), yellow centrally toward vertex; with long, erect white setae interspersed (part of them brownish toward apex). Vertex and area behind eyes with sculpturing as on frons (punctures slightly denser behind eyes); with white, bristly pubescence centrally, not obscuring integument, distinctly denser between antennal tubercles, short erect seta emerging from each puncture toward prothoracic margin; with dense, wide yellow pubescent band close to eyes; area behind lower eye lobes nearly glabrous close to prothorax; with sparse, long, erect, white and brownish setae interspersed. Genae finely, sparsely punctate, except smooth central area and apex; with yellow pubescence toward ventral surface, white toward frons, except glabrous smooth areas; with a few long, erect white setae interspersed. Postclypeus with sculpturing and pubescence as on anterior area of frons. Labrum finely, moderately abundantly punctate; with long and short, white setae not obscur- ing integument, and fringe of yellow setae on anterior margin. Gulamentum with a few long, erect white setae anteriorly. Outer side of mandibles with white pubescence partially obscuring integument on posterior half, interspersed with a few long, erect white setae, glabrous on anterior half. Distance between upper eye lobes 0.25 times length of scape; in frontal view, distance between lower eye lobes 0.80 times length of scape. Antennae (from base of scape to apex of antennomere VIII) 1.4 times elytral length, almost reaching elytral apex. Scape with white pubescence not obscuring integument (yellowish-white on some areas, especially ventrally), interspersed with long, erect yellowish-brown setae (whiter or browner depending on light intensity and angle of source). Pedicel and antennomeres III and IV with white pubescence not obscuring integument on lighter area (partially yellowish on some areas), brown on dark area. Remaining antennomeres with brown pubescence not obscuring integument, with short, decumbent white setae interspersed. Antennal formula (ratio) based on length of antennomere III: scape $=0.72$; pedicel $=0.18$; $\mathrm{IV}=0.84 ; \mathrm{V}=0.38 ; \mathrm{VI}=0.33 ; \mathrm{VII}=0.31 ; \mathrm{VIII}=0.29$.
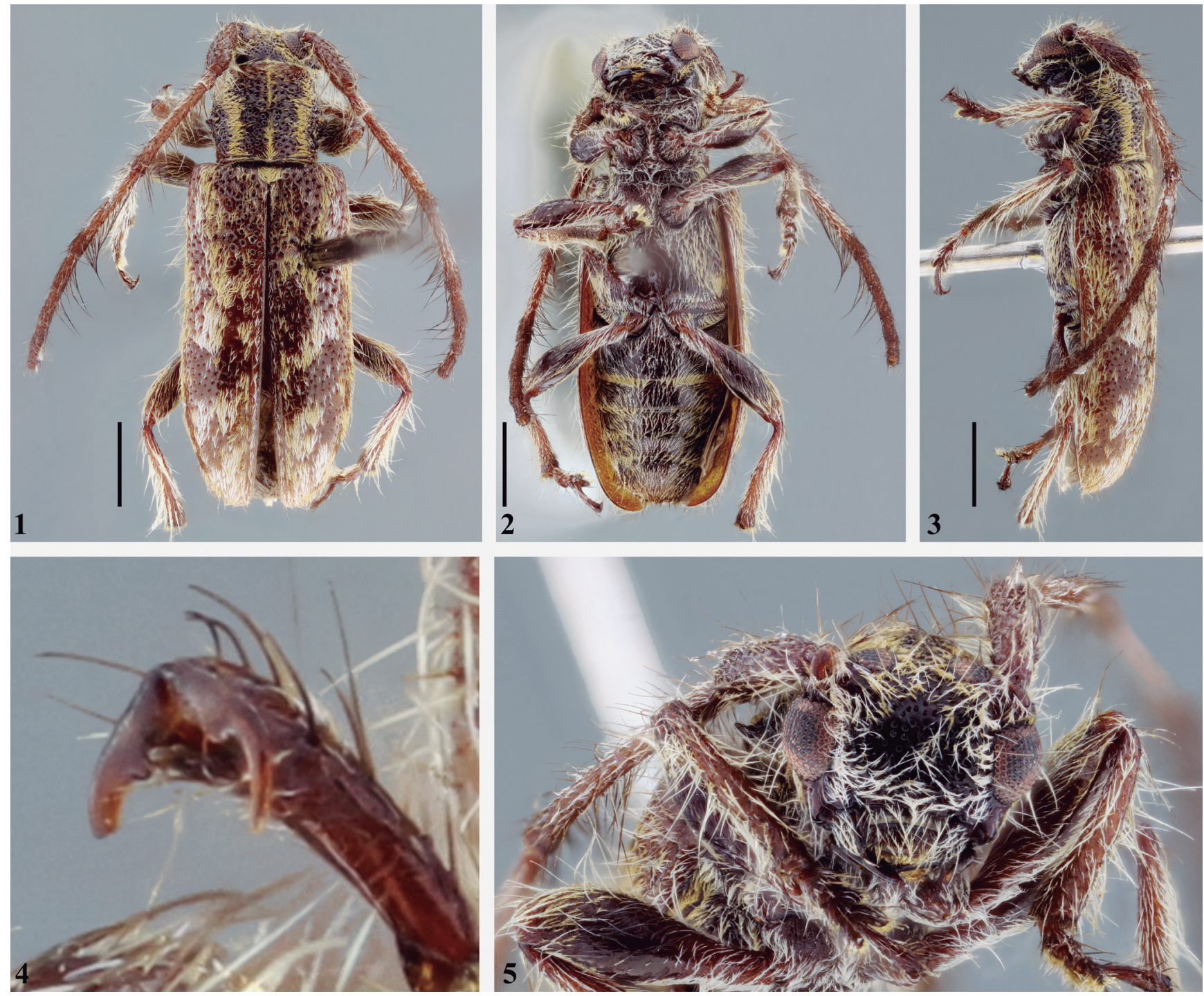

Figures 1-5. Cleidaria cleidae gen. nov. et sp. nov., holotype male. (1) Dorsal habitus; (2) Ventral habitus; (3) Lateral habitus; (4) Tarsal claws; (5) Head, frontal. 
Thorax: Pronotum coarsely, abundantly punctate; with three longitudinal yellow pubescent bands, central narrow and one wider on each side; remaining surface with sparse, short, sparse white setae, and small patches with yellow setae (both slightly more abundant laterally); remainder areas with long, sparse, erect white and
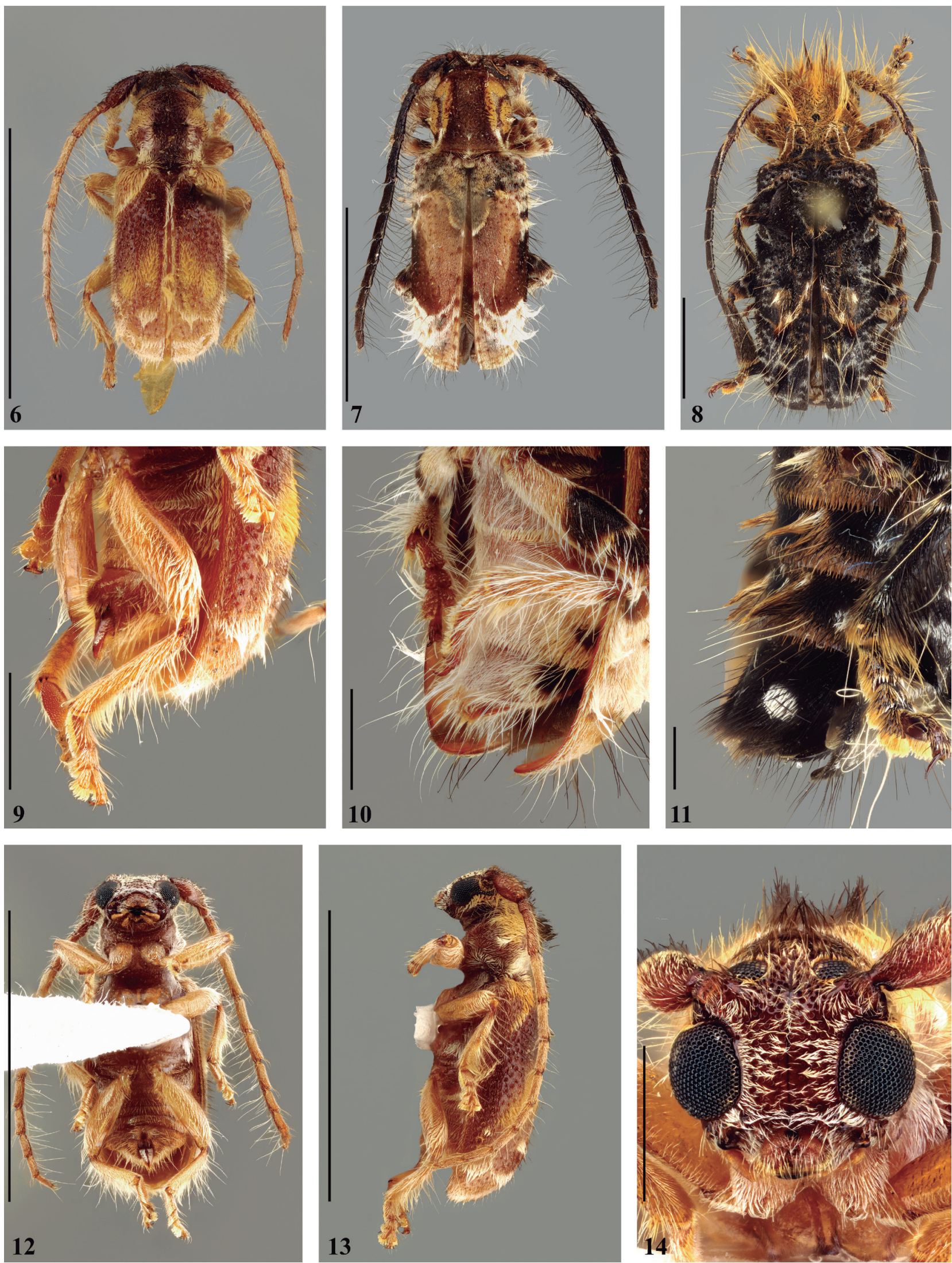

Figures 6-14. Obscenoides compta (Martins \& Galileo, 2005) comb. nov., male. (6) Dorsal habitus; (9) Abdomen, lateral; (12) Ventral habitus; (13) Lateral habitus; (14) Head, frontal. Desmiphora (Desmiphora) elegantula White, 1855, male: (7) Dorsal habitus; (10) Abdomen, lateral. Desmiphora (Desmiphora) fasciculata (0livier, 1792), male: (8) Dorsal habitus; (11) Abdomen, lateral. Scale bars: 6-8, 12-13=5 mm, 9-11, $14=1 \mathrm{~mm}$. 
brownish setae. Sides of prothorax with punctation as on pronotum; with sparse, short white setae, and some irregular patches with yellow pubescence on some areas; with long, erect white setae interspersed. Ventral surface of thorax with long, decumbent white setae partially obscuring integument on some areas, with yellow pubescence laterally, especially on metathorax. Metanepisternum and sides of metaventrite coarsely, moderately abundantly punctate. Scutellum slightly wider than long, with the anterior margin rounded, and yellow pubescence obscuring integument.

Elytra: Coarsely, densely punctate on basal half; punctation gradually finer, sparser toward apex; basal half with wide, nearly oblique yellow pubescent band dorsally, with stout white pubescent band adjacent to the outer side of former; dorsal surface of distal half with irregular maculae with yellow and white pubescence, separate on some areas, partially mixed in others; sides with longitudinal yellow pubescent band from about humerus to near apex; remaining surface of dorsal basal half with sparse yellow pubescence, and remaining surface of posterior half glabrous or with very sparse, short, white setae; erect setae mostly white laterally, and mostly yellowish-brown dorsally.
Legs: Femora with long, decumbent yellow setae dorsally, interspersed with long, erect white setae; with white pubescence laterally on basal third, sparse or nearly absent on remaining surface; with white pubescence on basal half of ventral surface, yellow laterally of distal half of ventral surface, glabrous on central area of distal half of ventral surface. Tibiae with long, abundant white setae dorsally and laterally, except yellowish-brown pubescence on distal third of mesotibiae; ventral surface of pro- and mesotibiae with short white pubescence on basal third, gradually yellowish-brown, with white setae interspersed toward apex; metatibiae with short white pubescence ventrally.

Abdomen: Ventrite I with white pubescence, moderately abundant, but not obscuring integument, except fringe of dense yellow pubescence laterally; ventrites II-IV with yellow pubescence laterally, white centrally, both abundant but not obscuring integument, except fringe of dense pubescence on the lateral posterior margin; ventrite $\mathrm{V}$ with yellow pubescence laterally, white centrally, both abundant but not obscuring integument; with a few long, erect, white setae laterally of ventrite I, yellowish-white laterally of ventrites II-IV, and yellowish-white and yellowish-brown setae laterally of ventrite $\mathrm{V}$.
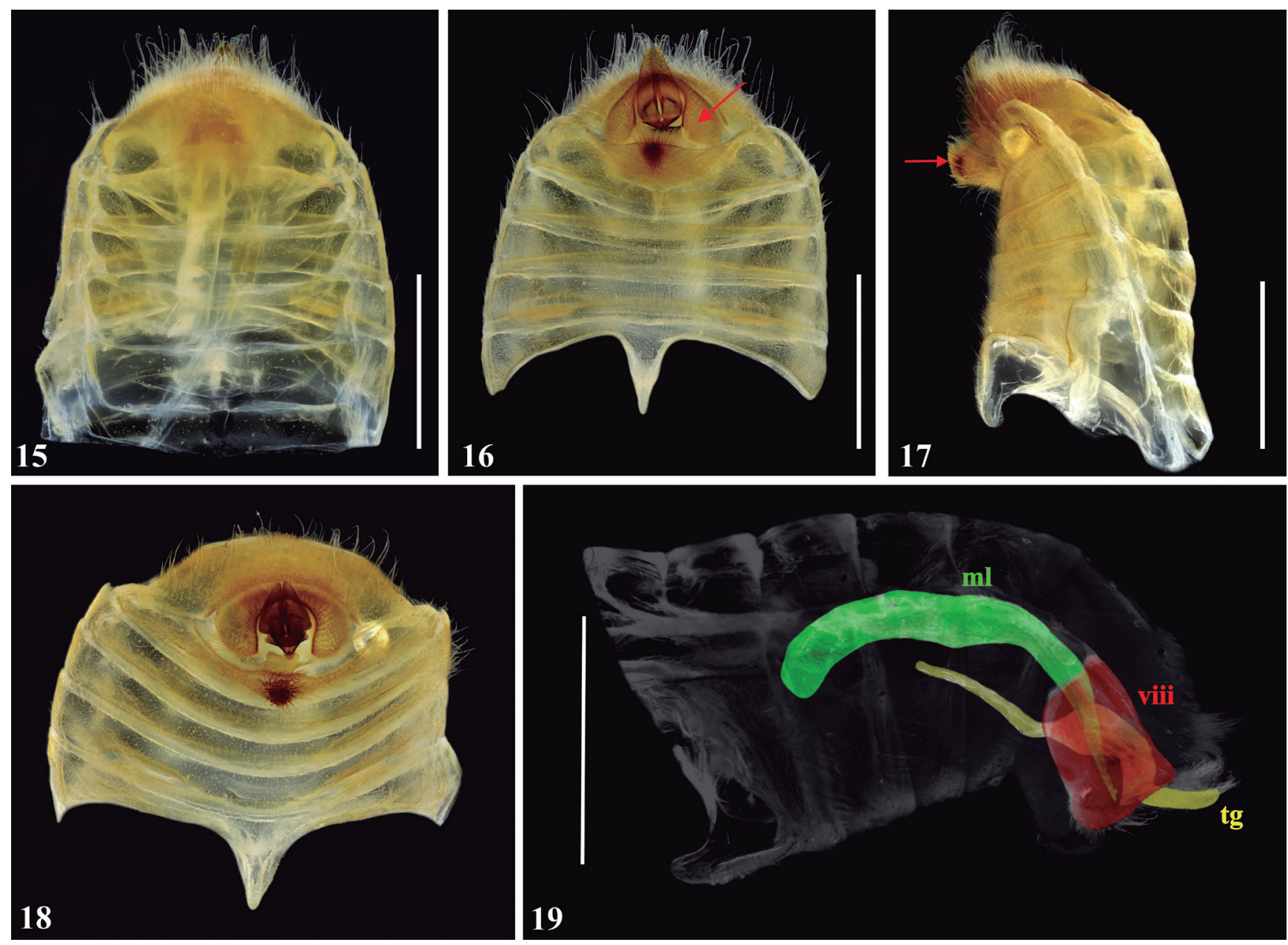

Figures 15-19. Obscenoides compta (Martins \& Galileo, 2005) comb. nov., male abdomen: (15) Dorsal; (16) Ventral with detailed tergite VIII; (17) Lateral with detailed tubercle at ventrite V; (18) Posterior; (19) Lateral, schema highlighting the internal position of the genitalia: $\mathrm{ml}$ (in green) = median lobe, viii (in red) = tergite $\mathrm{VIII}, \mathrm{tg}$ (in yellow) $=$ tegmen. Scale bars: $1 \mathrm{~mm}$. 
Dimensions ( $\mathrm{mm})$ : Total length, 5.80; prothoracic length, 1.20; anterior prothoracic width, 1.15; posterior prothoracic width, 1.20; maximum prothoracic width, 1.50; humeral width, 1.85; elytral length, 4.15 .

Etymology: The species epithet is in honor of Cleide Costa (MZSP) for her contributions to the knowledge of Coleoptera.

\section{Obscenoides gen. nov.}

(Figs. 6, 9, 12-14; 15-19; 20, 23, 26, 29)

Type species: Desmiphora (D.) compta Martins \& Galileo, 2005.

Description: Body with cylindrical shape. Frons transverse; palpi with apical segments fusiform. Antennal tubercles gradually elevated from median groove. Eyes coarsely faceted; lower eye lobes longer than genae; lower and upper eye lobes narrowly connected. Antennae slender with antennomeres gradually decreasing in length; with long, erect, moderately abundant setae; scape elongate, moderately widened toward apex; antennomere III shorter than scape; XI fusiform. Prothorax about as wide as long; sides with central tubercle. Procoxal cavities closed behind. Central area of prosternal process less than half diameter of procoxal cavity. Elytra parallel-sided; apex unarmed, jointly rounded; with long, erect setae throughout. Femora subfusiform; tibiae shorter than femora; metatarsomere I subequal to II + III.

Abdomen (Figs. 15-19): Abdominal ventrites I-IV subequal in length; $V$ with posterior median margin ventrally folded; with strongly elevated median tubercle with dense, short, thick setae apically (Fig. 17).
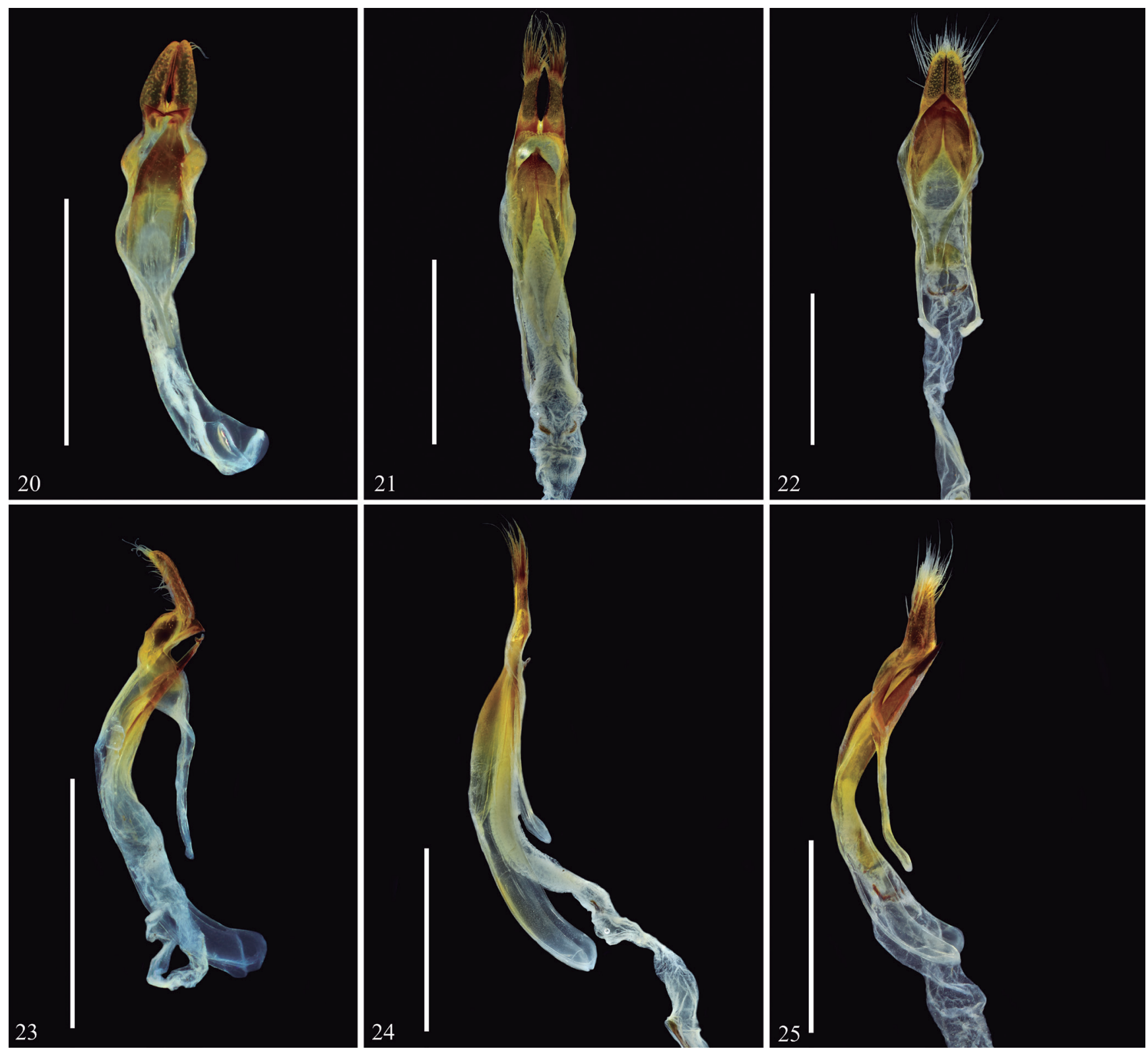

Figures 20-25. Tegmen and median lobe. Obscenoides compta (Martins \& Galileo, 2005) comb. nov. (20) Ventral; (23) Lateral. Desmiphora (Desmiphora) fasciculata (Olivier, 1792): (21) Ventral; (24) Lateral. Desmiphora (Desmiphora) elegantula White, 1855: (22) Ventral; (25) Lateral. Scale bars: $1 \mathrm{~mm}$. 
Male genitalia: Tergite VIII visible ventrally; heavily twisted around parameres (Fig. 16). Parameres exposed, with basal support flap; with long, erect, moderately abundant setae dorsally. Median lobe with a small hook-like projection apically (Fig. 29).

Female: Similar to males except for absence of abdominal tubercle, and with narrow central-longitudinal sulcus on ventrite $\mathrm{V}$.

Etymology: Latin, "Obscen" from Obscenum = indecent/ obscene; Greek, oides = form, likeness. The name refers to non-retractile parameres. Feminine gender.

Remarks: Martins \& Galileo (2005) characterized $D$. (D.) compta by having an evident central tubercle on abdominal ventrite $\mathrm{V}$ of males. In the same work, the authors compared $D$. (D.) compta with $D$. (D.) elegantula White, 1855 and D. (D.) pitanga Galileo \& Martins, 1998 (translated): "Desmiphora (D.) compta sp. nov. is characterized by the last urosternite of males with large central tubercle. By the glabrous or sparsely pubescent center of pronotum, with sides covered by dense pubescence, resembles to $D$. (D.) elegantula White, 1855 and differs by the absence of a crest on the inner side of the yellowish pubescence of prothorax, by the presence of glabrous area on each side of middle of pronotum, by the orange pubescent humeral area and by the absence of white
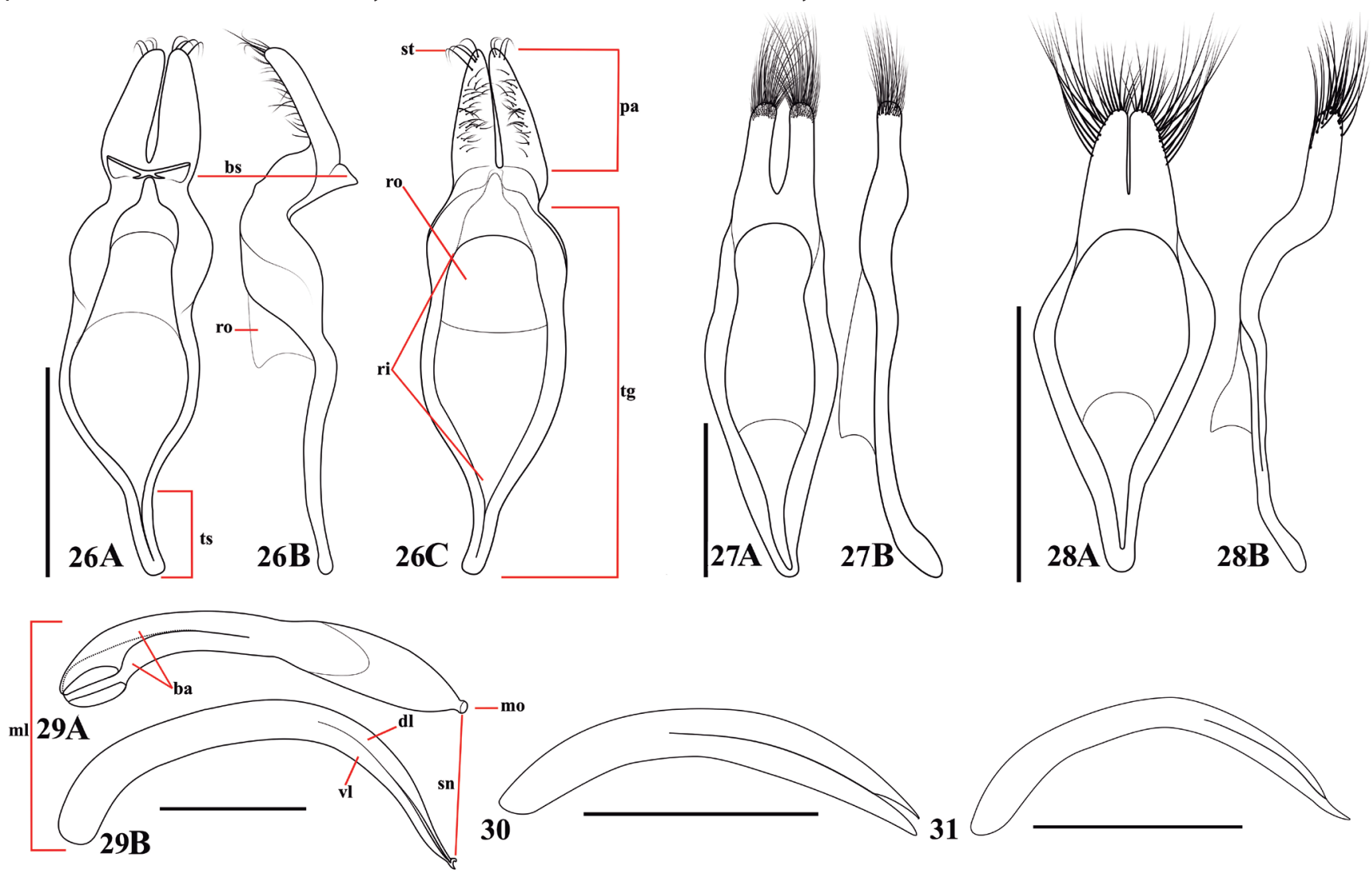

hair brushes in the apical part of elytra. The pronotal glabrous spots are similar those of $D$. (D.) pitanga Galileo \& Martins, 1998, but the color pattern easily separates the two species."

In addition to the tubercle on ventrite $\mathrm{V}$, mentioned by Martins \& Galileo (2005), the non-retractile parameres are extremely rare and we are unaware of other similar cases even in Cerambycidae. Although most species of Desmiphora were examined, for comparison purposes, we provide photograph of $D$. (D.) elegantula and D. (D.) fasciculata (Olivier, 1792) (type species of Desmiphora) (Figs. 7, 8, 10, 11).

In addition to non-retractile parameres, the new genus differs from Desmiphora by the presence of a support-flap on the parameres (Figs. 20, 23, 26a, b), which possibly has a function of, together with the tubercle on ventrite $\mathrm{V}$, avoiding the contact of parameres with the substrate, or it is a support structure for copulation. The new genus also differs by the setae of parameres present throughout the dorsal surface (Fig. 26c) (present only at the apex in the others species of Desmiphorini [e.g., Figs. 21, 22, 24, 25, 27, 28]); the median lobe in Obscenoides gen. nov. has a hook-like projection (Fig. 29), absent in other Desmiphora species and others genera (Figs. 30-31).

The genitalia in Cerambycidae is telescoped (as in other Coleoptera families), in other words, they can fit entirely within the abdomen (Wood, 1952). The males

Figures 26-31. Schemes of aedeagus. Obscenoides compta (Martins \& Galileo, 2005) comb. nov.: (26) Tegmen: A = Ventral, B = Lateral, C = Dorsal; (29) Median lobe: $A=$ Ventral; $B=$ Lateral. The acronyms correspond to: $b a=$ basal apophyses; $b s=$ basal support flap; $\mathrm{dl}=$ dorsal lobe; $\mathrm{ml}=$ median lobe; $\mathrm{mo}=$ median orifice; $\mathrm{pa}=$ parameres $; \mathrm{r}$ = ring part; $\mathrm{ro}=$ roof; $\mathrm{sn}=$ hook-like projection; $\mathrm{st}=$ setae; $\mathrm{tg}=$ tegmen; $\mathrm{ts}=$ tegmen struts; $\mathrm{vl}=$ ventral lobe. Desmiphora (Desmiphora) fasciculata (Olivier, 1792). (27) Tegmen: $A=$ Ventral; $B=$ Lateral; (30) Median lobe, lateral. Desmiphora (Desmiphora) elegantula White, 1855. (28) Tegmen: $A=$ Ventral; $B=$ Lateral; (31) Median lobe, lateral. 
genitalia have the typical Cucujiform shape, basically composed by a median lobe, tegmen divided into a ring part (the biggest), paired parameres and an internal sac (Ehara, 1954). The parameres are separated from each other and when in retracted position, the posterior portion of tegmen is located dorsal to median lobe, and tegminal struts pass ventrally around the median lobe (Ślipiński \& Escalona, 2013).

Because of its non-standard combination of characters, the genitalia of Obscenoides compta comb. nov. presumably play a significant role in mating behavior. Although there are few specific studies on the function of genitalic structures in Cerambycidae, according to Kingsolver (1970), the parameres in Bruchinae (Chrysomelidae) are used as guides to position the median lobe into the vaginal opening. When studying morphology and function of parameres in Cerambycidae and Chrysomelidae (both Chrysomeloidea), Hubweber \& Schmitt (2006) commented that the setae on parameres have a sensorial function to facilitate the release of sperm to the proper regions inside the female. The same authors identified the presence of small openings that possibly works in the glandular secretion.

\section{Obscenoides compta (Martins \& Galileo, 2005) comb. nov.}

Desmiphora (Desmiphora) compta Martins \& Galileo, 2005: 247; Wappes, Arias \& Nearns, 2009: 2; Wappes et al., 2013: 11; Wappes \& Arias, 2016: 5; Moura \& Von Groll, 2017: 451.

Material examined: PARATYPE + (MZSP): BOLIVIA, Santa Cruz: Buena Vista (4-6 km SSE, Flora \& Fauna Hotel), 01-15. III.2003, R. Clarke col.

Other material examined: Same data as paratype, 21-22.X.2008, R. Clarke col. (1 ơ', MZSP).

\section{Redescription}

Male: Head, scape, prothorax, ventral surface of mesoand metathorax, and mostly of abdominal ventrites dark brown; pedicel and antennomeres mostly reddish brown; posterior area of elytra reddish brown, gradually lighter toward apex; legs mostly reddish-brown.

Head: Frons with moderately sparse, decumbent yellowish-white pubescence; coarsely punctate. Median groove distinct from postclypeus to area behind eyes. Vertex and area behind eyes punctated as frons; with dense yellowish pubescence laterally, close to posterior margin of upper eye lobes; median area with erect brownish setae. Distance between upper eye lobes about the width of an upper eye lobe; upper eye lobes with seven rows of ommatidia. Antennae slightly exceeding the elytral apex. Scape and pedicel with yellowish pubescence dorsally, nearly glabrous ventrally; with moderately abundant, short, erect dark setae dorsally, and long, erect, sparse yellowish setae ventrally; flagellomeres with yellowish pubescence not obscuring integument, and long, erect yellowish setae at posterior external margin, and along entire inner side. Antennal formula (ratio) based on length of antennomere III: scape $=1.3$; pedicel $=0.4$; $I V=1.3 ; \mathrm{V}=1.0 ; \mathrm{VI}=0.9 ; \mathrm{VII}=0.8 ; \mathrm{VIII}=0.8, \mathrm{IX}=0.7, \mathrm{X}=0.7$, $\mathrm{XI}=0.7$.

Thorax: Pronotum coarsely, abundantly punctate; with two parallel tufts of blackish setae at middle; anterior half with area of yellowish pubescence laterally converging toward dorsal area; band of whitish pubescence from posterior margin, converging to middle, reaching blackish tufts; median posterior margin with dense row of erect blackish setae; remaining surface with sparse yellowish-white pubescence. Lateral margins of prothorax with rhomboid tubercle at middle; with sparse yellowish-white pubescence, except dense, triangular white macula close each tubercle. Mesanepisternum, metanepisternum and posterior sides of metaventrite with dense whitish pubescence. Scutellum with decumbent, elongated blackish setae on posterior margin, and sparse yellowish pubescence on remaining areas.

Elytra: Coarsely, densely punctate on anterior twothirds, punctures gradually sparser toward apex; suture carinate. Pubescence as follows: yellowish-brown pubescence on humerus, with oblique band projected from it dorsally; wide, obliquely divergent yellowish-brown pubescent band from about middle to posterior third; two tufts of white erect setae, one at about posterior third, another at posterior fifth; circular band of whitish pubescence connecting the two tufts laterally; and whitish pubescent band along anterior sutural quarter, becoming yellowish along suture toward posterior third, and whitish toward apex; remaining surface with sparse yellowish pubescence, and long, erect dark setae.

Legs: Femora with dense whitish pubescence, partially obscuring integument on some areas. Tibiae with dense whitish pubescence, with erect, elongated whitish setae interspersed. Abdomen (Figs. 15-19). Ventrites with moderately dense yellowish pubescence, denser laterally.

Male genitalia: Tergite VIII (Figs. 16, 18) with elongate setae at ventral fold. Tegmen about four times longer than wide, strongly sclerotized (Figs. 20, 23, 26, 29). Tegminal rings, in lateral view, strongly curved on anterior half, then strongly oblongly widened laterally, triangularly notched ventrally (Fig. 26B). Tegminal struts (Fig. 26A) about one-sixth tegmen total length. Parameres about one-third tegmen total length, gradually narrow distally; basal support flap slightly curved, strongly sclerotized ventrally. Median lobe (Fig. 29) strongly curved, about 1.1 times longer than tegmen in lateral view.

Dimensions ( $\mathbf{m m}$, male/female): Total length, 5.6/5.9-6.5; length of prothorax, 1.4/1.5-1.6; larger width of prothorax, 1.5/1.5-1.9; elytral length, 3.9/4.0-4.6; humeral width, 2.0/2.2-2.3. 


\section{DISCUSSION}

Although Cerambycidae has its classification based mainly on pre-evolutionary works, with characters resulting from convergences and other evolutionary phenomena, their importance and usefulness are still relevant to subordinate taxa such as Cleidaria cleidae gen. nov. et sp. nov.

As pointed out by Hubweber \& Schmitt (2009), due to the colorful pattern of cerambycids which are usually species-specific, taxonomists generally prefer to base their descriptions only on external morphology. Another point of view for this paradigm is the scarcity of material (many species are described based on the holotype solely) and for years, curators have been reluctant to allow dissection. This goes against trends in other beetle groups in which genitalia and other internal sclerotized structures are important source of taxonomical information for some 200 years (Wanat, 2007).

As some works suggest (e.g., Ehara, 1954; Fragoso 1985a, b; Fragoso et al., 1987; Hubweber \& Schmitt, 2006) the shape of Cerambycidae's genitals have phylogenetic signal. However, identifying patterns for grouping supraspecific taxa is a difficult task. By studying the genital morphology of a significant number of species, Fragoso (1985a) highlighted that there are few morphological patterns that allow grouping a large number of species. According to Hubweber \& Schmitt (2009): "the phylogenetic information provided by these structures may be better suited for inferring relationships among the smaller subfamilies". It is noteworthy that the scarcity of genitalia descriptions makes identifying patterns even more difficult.

As expected in a megadiverse beetle family, the genital morphology may be useful for taxonomical purposes. As suggested by Wanat (2007) the evolutionary changes in genitalia of Chrysomeloidea, as in others phytophagan superfamilies, are very complex with many evolutionary convergences.

The genital morphology of Obscenoides compta comb. nov. may highlight the need of thoroughly studying these structures and possibly indicate that their relevance is taxonomically underestimated. Summarizing, as the study of the genitalia of both, new and known cerambycids' species are provided, especially in phylogenetic studies, will be possible to understand its evolution, and identify patterns that can be used taxonomically.

\section{ACKNOWLEDGMENTS}

The first author is grateful for the grant 2017/15283-9, São Paulo Research Foundation (FAPESP). We are grateful to two anonymous reviewers and the editors, Dr. Sônia Casari (MZSP) and Dr. Gabriel Biffi (MZSP), for the valuable corrections and suggestions in the manuscript.

\section{AUTHORS' CONTRIBUTIONS}

All authors contributed equally.

\section{REFERENCES}

Breuning, S. 1974. Révision des Rhodopinini américains. Studia Entomologica, Rio de Janeiro, 17: 1-4: 1-210.

Ehara, S. 1954. Comparative anatomy of male genitalia in some cerambycid beetles. Journal of the Faculty of Science, Hokkaido University Series 6, Zoology, 12: 61-115.

Fragoso, S.A. 1985a. The terminalia as a basis for the classification of Cerambycidae (Coleoptera) subfamilies. Part I Terminology and genital morphology of Cerambyx cerdo L. Revista Brasileira de Entomologia, 29: 125-134.

Fragoso, S.A. 1985b. The terminalia as a basis for the classification of Cerambycidae (Coleoptera) subfamilies. Part II, Oxypeltinae. Revista Brasileira de Entomologia, 29: 165-168.

Fragoso, S.A.; Monné M.A. \& Seabra C.A.C. 1987. Preliminary considerations on the higher classification of Cerambycinae (Coleoptera, Cerambycidae), with nomenclatural alterations. Revista Brasileira de Biologia, 47: 189-202.

Hubweber, L. \& Schmitt M. 2006. Parameres - similarities and differences in Chrysomelidae and Cerambycidae (Coleoptera). Bonner Zoologische Beiträge, 54: 253-259.

Hubweber, L. \& Schmitt M. 2009. Differences in genitalia structure and function between subfamilies of longhorn beetles (Coleoptera: (erambycidae). Genetica, Dordrecht, 138(1): 37-43.

Kingsolver, J.M. 1970. A study of male genitalia in Bruchidae (Coleoptera). Proceedings of the Entomological Society of Washington, 72: 370-386.

Lacordaire, J.T. 1868 [1869]. Histoire Naturelle des Insectes. Genera des Coléopteres. Vol. 8. Paris, Librairie Encyclopedique de Roret. 552p.

Lacordaire, J.T. 1869. Histoire Naturelle des Insectes. Genera des Coléoptères, ou exposé méthodique et critique de tous les genres proposés jusqu'ici dans cet ordre dinsectes. Famille des Longicornes (suite). Paris, Librairie Encyclopédique de Roret. v. 6, Tome 9, pt. 1, 409p.

Lacordaire, J.T. 1872. Histoire naturelle des Insectes. Genera des Coléoptères, ou exposé méthodique et critique de tous les genres proposés jusquíi dans cet ordre d'insectes. Famille des Longicornes (fin). Paris, Librairie Encyclopédique de Roret. v. 6, Tome 9, pt. 2, 411p.

Linsley, E.G. \& Chemsak, J.A. 1984. The Cerambycidae of North America. Part VII, No. 1. Taxonomy and classification of the subfamily Lamiinae, tribes Parmenini through Acanthoderini. University of California, Publications in Entomology, 102: 1-258.

Martins, U.R. \& Galileo, M.H.M. 2005. Contribuição para o conhecimento dos Desmiphorini (Coleoptera, Cerambycidae, Lamiinae) da Região Neotropical. Papéis Avulsos de Zoologia, São Paulo, 45(19): 243-248.

Monné, M.A. \& Wappes, J.E. 2014. Description of Protumida insularis, a new genus and species of the tribe Desmiphorini (Coleoptera, Cerambycidae, Lamiinae) from Panama. Insecta Mundi, Gainesville, 374: 1-4.

Moura, L.A. \& Von Groll, E. 2017. Catalogue of Coleoptera type specimens housed in the collection of the Museu de Ciências Naturais, Fundação Zoobotânica do Rio Grande do Sul, Brazil. Zootaxa, 4318 (3): 439-473.

Roguet, J.P. 2019. Lamiinae. Available from: https://lamiinae.org. Access in: 18/12/2019.

Ślipiński, A. \& Escalona, H.E. 2013. Australian Longhorn Beetles (Coleoptera, (erambycidae). Introduction and subfamily Lamiinae. Volume 1. Collingwood, CSIRO Publ. 484p.

Tavakilian, G.L. \& Chevillotte, H. 2019. Titan: base de données internationale sur les Cerambycidae ou Longicornes. Available from: http://titan.gbif.fr/ index.html. Access in: 02/2020.

Tavakilian, G.L. \& Néouze, G.L. 2013. Nouvelles espèces d'Acanthoderini de Guyane (Coleoptera, Cerambycidae, Lamiinae). Les Cahiers Magellanes, 13: 38-73. 
Wanat, M. 2007. Alignment and homology of male terminalia in Curculionoidea and other Coleoptera. Invertebrate Systematics, 21: 147-171.

Wappes, J.E. \& Arias, J.L. 2016. Updated list of Coleoptera holotypes in Museo de Historia Natural, Noel Kempff Mercado, Universidad Autónoma "Gabriel Rene Moreno", Santa Cruz de la Sierra, Bolivia. Insecta Mundi, 497: 1-27.

Wappes, J.E.; Arias, J.L \& Nearns, E.H. 2009. List of Coleoptera holotypes in Museo de Historia Natural Noel Kembff Mercado, Universidad Autonoma
"Gabriel Rene Moreno", Santa Cruz de la Sierra, Bolivia. Insecta Mundi, Gainesville, 81: 1-8.

Wappes, J.E.; Lingafelter, S.W.; Monné, M.A. \& Arias, J.L. 2013. Additions to the known Vesperidae and Cerambycidae (Coleoptera) of Bolivia. Insecta Mundi, Gainesville, 319: 1-25.

Wood, S.L. 1952. Observations on the homologies of the copulatory apparatus in male Coleoptera. Annals of the Entomological Society of America, 45: 613-617. 